American Journal of Applied Sciences 8 (4): 362-367, 2011

ISSN 1546-9239

(C) 2010 Science Publications

\title{
Evaluation of a Dual-Purpose Chemical Applicator for Paddy Fields
}

\author{
${ }^{1}$ Mohammed Shu'aibu Abubakar, ${ }^{1}$ Desa Ahmad, ${ }^{1}$ Othman Jamarei, \\ ${ }^{2}$ Sulaiman Samsuddin and ${ }^{3}$ Misron Norhisam \\ ${ }^{1}$ Department of Biological and Agricultural Engineering, \\ ${ }^{2}$ Department of Mechanical and Manufacturing Engineering, \\ ${ }^{3}$ Department of Electrical and Electronic Engineering, \\ Faculty of Engineering, University Putra Malaysia, \\ 43400 UPM Serdang, Selangor, Malaysia
}

\begin{abstract}
Problem statement: One of the major problems of rice production is the shortage of labor resulting from migration from rural to urban areas, making it very difficult to meet peak demands for paddy production. In most developing countries of Southeast Asia, agricultural mechanization of paddy field operation is mostly carried out using conventional machines. For example in rice production powerintensive operations such as water pumping, land preparations, transplanting seedlings, harvestings and threshing are being mechanized but other operations like fertilizer and chemical (pesticides) applications are not yet fully mechanized, rather they are performed manually with motorized backpack knapsack sprayers which have many disadvantages. The main objective of this study was to develop and evaluate a new concept dual-purpose chemical applicator for paddy fields farmers in order to complement the labor shortage during the peak period. Approach: A dual-purpose chemical applicator for flooded paddy field was evaluated using the S341.4 Standard in respect to the distribution patterns/droplet sizes and uniformity of spreading/spraying for the chemical application to boost agricultural mechanization in rice production and also to overcome the safety concern of hazardous spray drift during chemical application by the paddy farmers. The dual purpose applicator was mounted on a high clearance prime mover. The machine performances for both granular and liquid chemical application were reported. Results: Results for urea granular chemical indicate that at low $\left(40 \mathrm{~kg} \mathrm{ha}^{-1}\right)$ and high $\left(120 \mathrm{~kg} \mathrm{ha}^{-1}\right)$ rates and $550 \mathrm{rpm}$ disc speed distribution pattern skewed to the left whereas the distribution pattern shape at medium $\left(80 \mathrm{~kg} \mathrm{ha}^{-1}\right)$ rates was good flattop. At high rate $\left(120 \mathrm{~kg} \mathrm{ha}^{-1}\right)$ and $1000 \mathrm{rpm}$ disc speed, mean distribution pattern became poor (M-shape) and also at low and medium application rates the distribution pattern shapes lopsided to the left. For NASA glyphosate liquid chemical herbicide, the average values of (VDM) and (NMD) were 108 and $79 \mu \mathrm{m}$ at $80 \mathrm{lt} / \mathrm{ha}$ application rate and $5000 \mathrm{rpm}$ rotary disc speed and 185 and $119 \mu \mathrm{m}$ at $80 \mathrm{lt} / \mathrm{ha}$ application rate $3000 \mathrm{rpm}$ rotary disc speed. Conclusion: The experimental results from the experimental tests suggest that the average effective field capacity for the equipment with a prime mover was found to be $0.89 \mathrm{ha} \mathrm{h}^{-1}$ or $7.12 \mathrm{ha} /$ man-day for an $8 \mathrm{~h}$ working day.
\end{abstract}

Key words: Dual-purpose, chemical application, paddy field, spinner spreaders, particle trajectories, particle dynamics, Analysis Of Variance (ANOVA), radial straight vanes, Coefficient of Variation (CV), calibrating granular broadcaster, power-intensive operations, knapsack sprayers, urban areas, analytical models

\section{INTRODUCTION}

Agriculture is one of the most important economic sectors for many developing countries of Southeast Asia. A large proportion of the population is involved in agriculture. However, this number has declined in the last ten years because of the rapid expansion in the industrial, construction and tourism sectors. Consequently, labor has been drawn from the agricultural sector to others that resulted in labor shortages during the peak farming seasons. One of the major problems of rice production is the shortage of labor resulting from migration from rural to urban areas, making it very difficult to meet peak demands for

Corresponding Author: Mohammed Shu'aibu Abubakar, Department of Biological and Agricultural Engineering, Faculty of Engineering, University Putra Malaysia, 43400 UPM Serdang, Selangor, Malaysia, Tel: +60172122985, Fax: 603-8946 6425 
paddy production (Kanetani and Fauzi, 1991; Cho, 2010). Meanwhile mechanization is needed to replace the labor which is not available or is very expensive (Mohod et al., 2010; Kanetani and Fauzi, 1991). In Malaysia agricultural mechanization of paddy field operation is mostly carried out using conventional machines also in rice production power-intensive operations such as water pumping, land preparations, transplanting seedlings, harvestings and threshing are being mechanized but other operations like fertilizer and chemical (pesticides) applications are not yet fully mechanized, rather they are performed manually with motorized backpack knapsack sprayers which have many disadvantages. These include; lack of uniformity of input distribution applied to the crops, depending on high number of labor and drudgery in handling and loading of inputs on the field (Omar et al., 2011; Razak et al., 2011; Kanetani and Fauzi, 1991).

The performance of spinner spreaders has been widely investigated. Studies have typically focused on analytical models for particle trajectories on and off of the spinner (Liedekerke et al., 2006; Liedekerke et al., 2009; Dongbang et al., 2010). Several authors have reported the problems of particle dynamics on a spinning disc in their studies of the impact of different parameters on the spreading and improvement on operation/control of centrifugal fertilizer spreaders in agriculture. Patterson and Reece examined the sliding motion and rolling motion of a single spherical granular material on a flat rotary disc equipped with radial straight vanes while neglecting particle bounce and assuming a near center feed. They developed models to describe particle motion on the spinner disc and found reasonable agreements between the model predictions and experimental results. They also reported that the particle's radial velocity depends on the shape and the friction coefficient between a granular material and a rotary disc. For the same disc configuration, Inns and Reece showed that if a granular material begins its motion at a certain distance from the center of the disc, friction between the granular material and rotary disc can be neglected because the vertical velocity of the granular material is not lost on impact. Therefore, the granular material is moving up or down the vane surface until it leaves the rotary disc. Due to the physical discomfort and awareness of health risk associated with granular fertilizer and pesticide application such as operators' hazard when having direct contact of chemicals during field operation (Juste et al., 1990; Matthews, 2000). Nowadays, there has been a growing concern about the environmental problems (such as air and water pollution and decline in biodiversity) associated with the application of mineral fertilizer and pesticides (Matthews, 2000; Yahya et al., 2007; Snow and Ghaly 2008). For these reasons, accurate and uniform application of fertilizer/pesticides is absolutely important in minimizing environmental problems and costs. Over-doses can harm the environment seriously, as well as the crop itself. Consequently, the application methods of fertilizer/pesticides and the uniformity of the spread pattern have become important research topics in agricultural engineering (Yahya et al., 2007; Mohammadi, 2006; Ramesh and Shanmugan, 2011). A lot of effort on the influence of machine characteristics on the spread pattern has been done by Olieslagers et al. (1996). Pearson found that spinning disc sprayers gave effective spray droplets with $250 \mu \mathrm{m}$ VMD than lower values of VMDs. Uremis et al. (2004) reported that 250-500 $\mu \mathrm{m}$ drop diameters for herbicide applications which is easier to deliver to the target surfaces. The high volume application methods used by some farmers to apply chemicals could result in higher costs compared to using low volume method, hence the development of dual purpose equipment for granular fertilizer and pesticides application in the paddy field to address the problems of cost in paddy production and environmental pollution. Despite the fact that there are many equipment developed to distribute granular material, none has been developed to date which can effectively spread granular material such as granular fertilizer and as well as spray liquid materials such as, liquid herbicides in the rice crop production processes. Furthermore no equipment have been developed commercially which can distribute non- pressurized liquid on the crops. Most available liquid spreaders distribute liquid under pressure by nozzles and backpack with some type of pumping device which help to maintain enough pressure to push the liquid out of the nozzles on the crops. These pressurized devices make it very difficult to control the distribution, resulting inconvenient in backing heaving weight equipment, operator health hazard, spray drift hazard and consequently damaging the crop and the environment. This study presents the evaluation of a dual-purpose chemical applicator for paddy fields in respect to the distribution patterns/droplet sizes and uniformity of spreading/spraying for the chemical application.

Description of the chemical applicator: The chemical applicator consists of a hopper, orifices, rotary discs and electric motor Fig. 1. The applicator employs the use of two rotary discs rotating in an opposite direction driven by 0.204 hp electric motors (TM80-15150) and the rotational velocity can be varied continuously from 
Am. J. Applied Sci., 8 (4): 362-367, 2011

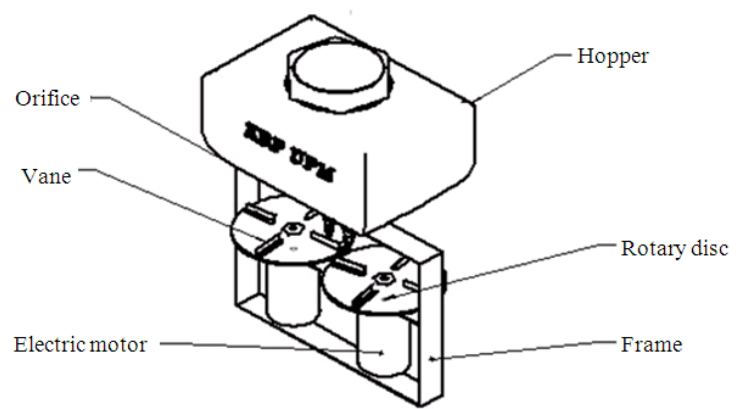

Fig. 1:3D drawing of the dual-purpose rotary disc chemical applicator

almost zero to above 5000 rpm by means of a rheostat speed controller. Chemical materials (granular or liquid) inside the hopper fall freely by gravity through the orifices and drop directly on the rotating discs (impeller) subsequently are applied to the field. The disc is fitted with vanes for granular application and rotates at a speed of 550 and $1000 \mathrm{rpm}$ while for liquid a plane flat disc rotates at a speed of 3000 and 5000 rpm to atomize liquid into fine spray. The centrifugal force of the rotary disc throws the material in an arc pattern over a distance to the right, front and to the left.

\section{MATERIALS AND METHODS}

Rotary disc and chemical (granular and liquid) characteristics (such as cone angle, disc diameter, vane length, particle size, moisture content, density, viscosity, surface tension, coefficient of friction) were taken into considerations during the equipment development. The chemical applicator distribution tests Fig. 2 and 3 were conducted as recommended by ASAE Standard S341.4 Procedure for Measuring Distribution Uniformity and Calibrating Granular Broadcaster Spreaders in which array of collection trays were used for performing the tests (Uremis et al., 2004). This is because outdoor testing is the most representative of what performance is achievable in the field. A total of 36 transverse tests were conducted. Six tests each for both urea granular chemical and NASA glyphosate liquid chemical were carried out. Each test was repeated three times and the mean values were reported. The Coefficient of Variation (CV) for the transverse spread pattern is commonly used to ascertain an acceptable working (swath) width for the chemical applicator. The $\mathrm{CV}$ is the measure of the overall uniformity of the chemical application distribution pattern and was determined by overlapping the transverse distribution pattern at meter intervals working widths, the sample mean and standard deviation of the overlapped application rate were
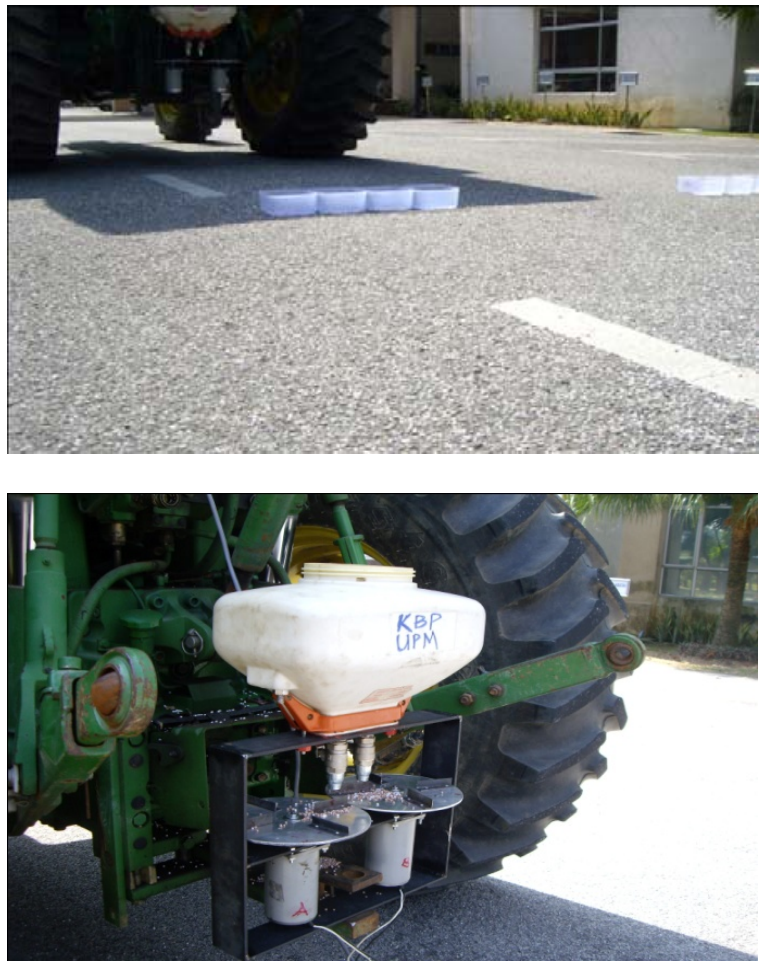

Fig. 2: Collection trays were removed on each of centerline to allow the prime mover wheels pass through

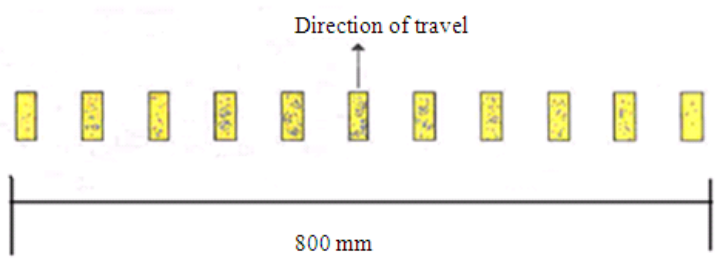

Fig. 3: Arrangement of water-sensitive paper for spray droplet collection

divided. The lower the $\mathrm{CV}$, the more uniform the distribution pattern.

This study uses Water-Sensitive Paper (WSP) to evaluate the droplet sizes formed by the dual-purpose rotary disc chemical applicator. The water-sensitive paper images were captured using high resolution camera 1:1.4/12.5m (HF12.5HA-1B) after allowed to dry for 30 minutes and then scanned using Program FlexScan 2D. The percentage spray droplets cover, number of droplets per square centimeters, size distribution of droplets and volume/mass deposited, droplet density per unit area, the VMD and NMD of their spectrum on each study were estimated and 
Am. J. Applied Sci., 8 (4): 362-367, 2011

analyzed using MATLAB software program. The VMD and NMD of the spray droplet spectrum were determined to ascertain the spray characteristics. Before the experiment the applicator was calibrated into three different flow rates for both granular and liquid chemicals. The openings of the orifices for the applicator were set at position low (40 kg/ha), medium (80 kg/ha) and high (120 kg ha) for urea granular fertilizer and low (40 lt/ha), medium (60 lt/ha) and high (80 lt/ha) for NASA glyphosate liquid chemical herbicide. These application rates were obtained from the adjusting of the chemical flow onto rotary discs by manually operated valves to achieve constant application rate and were deemed as typical target operator of the equipment. The disc rotary speed was set at 550 and $1000 \mathrm{rpm}$ and 3000 and $5000 \mathrm{rpm}$ for urea granular chemical and NASA glyphosate liquid chemical respectively. Analysis Of Variance (ANOVA) was conducted for each of these uniformities using SAS 9.2 statistical software to identify statistical significant differences between the various combinations.

\section{RESULTS AND DISCUSSION}

Table 1 and 2 show the mean values of the Coefficient of Variation (CV) for the urea granular distribution uniformity and the volume median diameter for the liquid chemical. The CV of $16 \%$ was obtained at the overlapping transverse distance of $2 \mathrm{~m}$ and combinations of $550 \mathrm{rpm}$ rotary disc speed and $80 \mathrm{~kg}$ $\mathrm{ha}^{-1}$ application rate Table 1 . The best liquid chemical Coefficient of Uniformity (CU) was obtained at the combinations of $5000 \mathrm{rpm}$ rotary disc speed and 80 lt/ha application rate Table 2.

Results for the urea granular chemical showed that the mean values of distribution patterns varied in shape at three different application rates (Fig. 4 and 5). Increased in application rates and rotary disc speed caused the change in distribution patterns. Figure 5 shows that at low (40 kg ha $\left.{ }^{-1}\right)$ and high $\left(120 \mathrm{~kg} \mathrm{ha}^{-1}\right)$ rates and $550 \mathrm{rpm}$ disc speed distribution pattern skewed to the left whereas the distribution pattern shape at medium $\left(80 \mathrm{~kg} \mathrm{ha}^{-1}\right)$ rates was good flattop. While at high rate $\left(120 \mathrm{~kg} \mathrm{ha}^{-1}\right)$ and $1000 \mathrm{rpm}$ disc speed, mean distribution pattern became poor (M-shape) and also at low and medium application rates the distribution pattern shapes lopsided to the left Fig. 5. It was observed that as the application rate increased from low through the medium to the high, the distribution pattern changed from low left sided to devastating peaks in the center pattern. Also experimental results revealed that when the application rate increased together with the increase of disc rotational speed the distribution pattern became

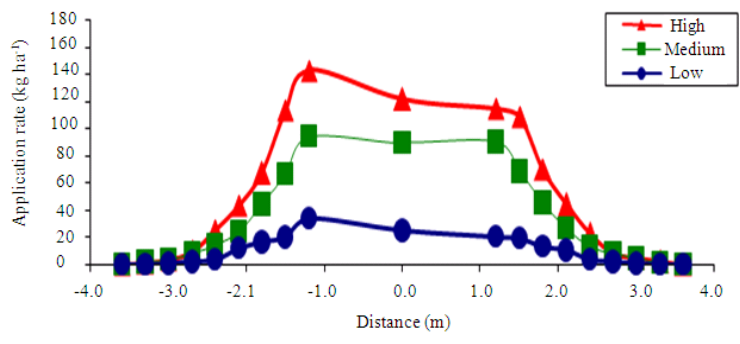

Fig. 4: Urea granular distribution patterns from 3 different application rates at $550 \mathrm{rpm}$ disc rotary speed

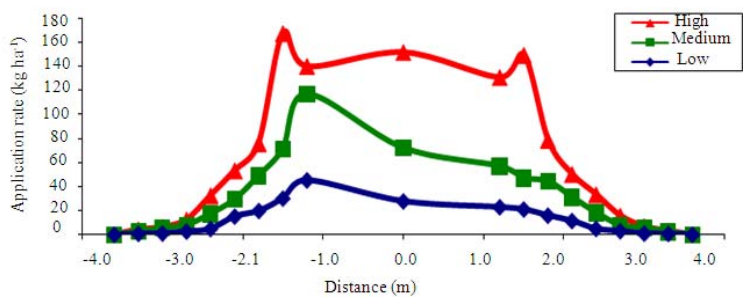

Fig. 5: Urea granular distribution patterns from 3 different application rates at $1000 \mathrm{rpm}$ disc rotary speed

Table 1: Average values of coefficient of variation (CV) for the urea granular chemical

\begin{tabular}{lcll}
\hline $\begin{array}{l}\text { Rotary disc } \\
\text { speed (rpm) }\end{array}$ & $\begin{array}{l}\text { Application } \\
\text { rate }(\mathrm{kg} / \mathrm{ha})\end{array}$ & $\begin{array}{l}\text { Coefficient } \\
\text { of variation } \\
(\mathrm{CV})(\%)\end{array}$ & $\begin{array}{l}\text { Distance } \\
(\mathrm{m})\end{array}$ \\
\hline 550 & 40 & 22 & 3 \\
& 80 & 16 & 2 \\
& 120 & 42 & 5 \\
1000 & 40 & 25 & 4 \\
& 80 & 38 & 4.5 \\
& 120 & 63 & 6.5 \\
\hline
\end{tabular}

Table 2: Average values of VMD, NMD and ratio of VMD and NMD for NASA glyphosate liquid chemical

\begin{tabular}{lllll}
\hline $\begin{array}{l}\text { Rotary disc } \\
\text { speed (rpm) }\end{array}$ & $\begin{array}{l}\text { Application } \\
\text { rate }(\mathrm{lt} / \mathrm{ha})\end{array}$ & $\mathrm{VMD}(\mu \mathrm{m})$ & $\mathrm{NMD}(\mu \mathrm{m})$ & $\begin{array}{l}\text { UC } \\
(\mathrm{VMD} / \mathrm{NMD})\end{array}$ \\
\hline 3000 & 40 & 272 & 180 & 1.51 \\
& 60 & 218 & 148 & 1.47 \\
5000 & 80 & 185 & 119 & 1.55 \\
& 40 & 182 & 123 & 1.48 \\
& 60 & 134 & 92 & 1.46 \\
& 80 & 108 & 79 & 1.37 \\
\hline
\end{tabular}

worst more and more. This agreed with the work of Aphale et al., 2003 and Grift et al., 2006, that reported that the mean distribution width increased with an increase in the disc rotational speed. They also reported that the distribution pattern uniformity is sensitive to some variations such as the increased in rotational speed of the disc. 


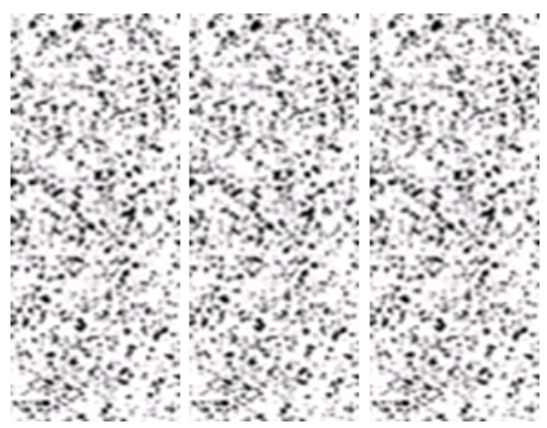

Fig. 6: Droplet size (VDM $108 \mu \mathrm{m})$ at $80 \mathrm{lt} / \mathrm{ha}$ rate and $5000 \mathrm{rpm}$ rotary disc speed

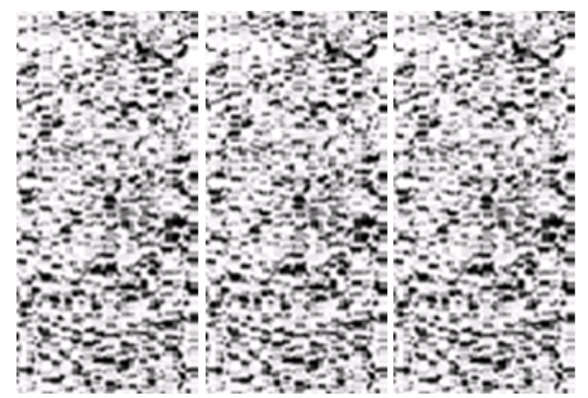

Fig. 7: Droplet size (VDM $185 \mu \mathrm{m})$ at 80 lt/ha rate $3000 \mathrm{rpm}$ rotary disc speed

For NASA glyphosate liquid chemical herbicide, the average values of VDM and NMD were 108 and 79 $\mu \mathrm{m}$ at $80 \mathrm{lt} / \mathrm{ha}$ application rate and $5000 \mathrm{rpm}$ rotary disc speed and 185 and $119 \mu \mathrm{m}$ at $80 \mathrm{lt} / \mathrm{ha}$ application rate $3000 \mathrm{rpm}$ rotary disc speed. Figure 6 shows that the droplet size with VDM of $108 \mu \mathrm{m}$ at 80lt/ha rate and $5000 \mathrm{rpm}$ rotary disc speed. Figure 7 presents the droplet size with VDM of $185 \mu \mathrm{m}$ at $80 \mathrm{lt} / \mathrm{ha}$ rate 3000 rpm rotary disc speed. It was found that the Volume Median Diameter (VMD) of the spray droplet sizes decrease with increasing liquid flow rate and disc rotational speed. This shows that the dual-purpose rotary chemical applicator converts more liquid into fine droplets in comparison with that of reported results for motorized knapsack with flat fan pressure nozzles sprayers with $60-70 \%$ droplets larger than $250 \mu \mathrm{m}$. Lefebvre found droplets size in the range of 120-300 micron in VMD be the most efficacious for chemical application. Also the new equipment average effective field capacity of the chemical application using high clearance prime mover was $7.12 \mathrm{ha} /$ man-day for a $8 \mathrm{~h}$ working day, compare to the motorized knapsack sprayer in addition to cost of labor, covered only 1.2 ha/man-day which is 6 times lower than when the new equipment was used. Statistically, the effect of flow rate and disc speed was significant at $\mathrm{P}<0.01$ level for all combinations.

\section{CONCLUSION}

The study concluded that the distribution patterns of the dual-purpose rotary disc granular fertilizer do vary with change in application rate and rotary disc speed, also a spray of almost uniform drop size is formed when a liquid chemical is atomized under suitable conditions and the machine has the potential of addressing the risk to human health and the environment. It could be used for the application of both granular and liquid chemicals by the rice growers.

\section{ACKNOWLEDGMENT}

This study is classified under the Institute of Higher Learning Project, IHL (FRGS-Fundamental Research Grant Scheme) Project No 07-10-07-435FR. The authors are grateful to the authority of University Putra Malaysia for granting the fund for the research project and also School of Graduate Studies for awarding Graduate Research Fellowship (GRF).

\section{REFERENCES}

Aphale, A., N. Bolander, J. Park, L. Shaw and J. Svec et al., 2003. Granular fertiliser particle dynamics on and off a spinner spreader. Biosyst. Eng., 85: 319-329. DOI: 10.1016/S1537-5110(03)00062-X

ASAE Standards, 2009. Procedure for measuring distribution uniformity and calibrating granular broadcast spreaders. A. Soci. Agricultural Engin. Standards, S341.3, St. Joseph, Mich.

Cho, Y.S., 2010. Germination characteristics of Korean and Southeast Asian redrice (Oryza sativa L.) seeds as affected by temperature. Asian J. Plant Sci., 9: 104-107.

Dongbang, W., W. Pirompugd and K. Triratanasirichai, 2010. The drying kinetics of chilies using a rotating fluidized bed technique. Am. J. Applied Sci., 7: 1599-1606. DOI: 10.3844/ajassp.2010.1599.1606

Grift, T.E., G. Kweon, J.W. Hofstee, E. Piron and S. Villette, 2006. Dynamic friction coefficient measurement of granular fertilizer particles. Biosyst. Engin. 95: 507-515.

Juste, F., S. Sanchez, R. Ibanez, L. Val and G. Garcia, 1990. Measurement of spray deposition and efficiency of pesticide application in citrus orchards. J. Agric. Eng. Res., 46: 187-196. DOI: 10.1016/S0021-8634(05)80125-8

Kanetani, Y. and M.B.H.M Fauzi, 1991. Mechanized direct seeding of rice in Muda, Malaysia. JARQ 25: 209-213.

Liedekerke, P.V., E. Tijskens, E. Dintwa, F. Rioual and J. Vangeyte et al., 2009. DEM simulations of the particle flow on a centrifugal fertilizer spreader. Powder Technol., 190: 348-360. DOI: 10.1016/j.powtec.2008.08.018 
Liedekerke, P.V., E. Tijskens, E. Dintwa, J. Anthonis and H. Ramon, 2006. A discrete element model for simulation of a spinning disc fertilizer spreader I. single particle simulations. Powder Technol., 170: 71-85. DOI: 10.1016/j.powtec.2006.07.024

Matthews, G.A., 2000. Pesticide Application Methods. 3rd Edn., John Wiley and Sons, USA., ISBN-10: 0632054735, pp: 432.

Mohammadi, I.M., 2006. Agricultural Waste Management Extension Education (AWMEE) the ultimate need for intellectual productivity. Am. J. Environ. $\quad$ Sci., $\quad 2$ : $10-14 . \quad$ DOI: 10.3844/ajessp.2006.10.14

Mohod, A., S. Jain and A.G. Powar, 2010. Energy option for small scale cashew nut processing in India. Energy Res. J., 1: 47-50. DOI: 103844/erjsp.2010.47.50

Olieslagers, R., H. Ramon and J.D. Baerdemaeker, 1996. Calculation of fertilizer distribution patterns from a spinning disc spreader by means of a simulation model. J. Agric. Eng. Res., 63: 137-152. DOI: 10.1006/jaer.1996.0016

Omar, R., N.A. Rahim and A. Ahmad, 2011. Voltage swells improvement in low voltage network using dynamic voltage restorer. Am. J. Applied Sci., 8: 55-62. DOI: 10.3844/ajassp.2011.55.62
Ramesh, S.M. and D.A. Shanmugam, 2011. Comparison and analysis of discrete cosine transform based joint photographic experts group image compression using robust watermarking algorithm. Am. J. Applied Sci., 8: 63-70. DOI: 10.3844/ajassp.2011.63.70

Razak, N.A., S.M. Tumin and R. Tajuddin, 2011. Effect of temperature on the color of natural dyes extracted using pressurized hot water extraction method. Am. J. Applied Sci., 8: 45-49. DOI: 10.3844/ajassp.2011.45.49

Snow, A.M. and A.E. Ghaly, 2008. A comparative study of the purification of aquaculture wastewater using water hyacinth, water lettuce and parrot's feather. Am. J. Applied Sci., 5: 440-453. DOI: 10.3844/ajassp.2008.440.453

Uremis, I., A. Bayat, A. Uludag, N. Bozdogan and E. Aksoy et al., 2004. Studies on different herbicide application methods in second-crop maize fields. Crop Prot., 23: 1137-1144. DOI: 10.1016/j.cropro.2004.05.004

Yahya, A., M. Zohadie, D. Ahmad, A.K. Elwaleed and A.F. Kheiralla, 2007. UPM indoor tyre traction testing facility. J. Terramech., 44: 293-301. DOI: 10.1016/j.jterra.2007.03.002 